\title{
Bilateral Wyburn-Mason Syndrome Presenting with Macular Edema
}

\author{
Omer Othman Abdullah
}

M.B.Ch.B/MD/FICO VR, Vitreoretinal surgeon and medical retina specialist, Phacoemulsification trainer, Ibinsina modern eye and retina center, Ministry of health, Erbil, Iraq

DOI: 10.36348/sjm.2020.v05i06.004 | Received: 05.06.2020 | Accepted: 15.06.2020 | Published: 24.06 .2020

*Corresponding Author: Omer Othman Abdullah

\section{Abstract}

The Wyburn-Mason or Bonnet-Dechaume-Blanc syndrome is a sporadic illness which is a type of phakomatosis, usually present as unilateral arteriovenous malformations (AVM), for the first defined by Magnus in 1874 as retinal AVM later in 1932 another description gave by Yates and Payne; as an AVMs of the retina and cerebral vasculature, while in 1937 Bonnet, Dechaume and Blanc defined as AVM involving facial, retinal and brain blood vessels, then in 1943 all literature revised by Wyburn-Mason to put together to his case reports, therefore, the name of Bonnet-Dechaume-Blanc syndrome given in France, but in English articles entitled as Wyburn-Mason syndrome [1]. At that time, due to a deficiency in diagnostic imaging techniques, all the diagnosis were performed by clinical findings, operation, or autopsy [2]. Usually, it is a unilateral disorder comprising of three distinct components: orbit, brain (ipsilateral to the retina) and face, in the face; the sensory region of the trigeminal nerve distribution involved, that takes the shape of naevi which might be wholly formed and illness, is complete, or the naevi might be faint or absent, the latter regarded as an incomplete disease $[1,3]$ but rarely a bilateral involvement encountered with an asymmetrical grade of malformation [4]. The pathology starts in the early embryonic period, and if vascular dysgenesis encountered can lead to a wide range of neurocutaneous vascular defects in the cerebrum or ocular or both [2]. When the disorder reaches the last stage, the AVM can compress the optic nerve causing impaired perfusion, ischemia eventually optic atrophy [2]. Another explanation for visual loss is glaucoma as a result of elevated vascular pressure, neovascularization resulting from ischemia, which might lead to vitreous hemorrhage [5]. Archer et al., staged the disease into three groups [6-8]: Group 1 (AVM cannot be detected clinically). Group 2 (Clinically seen as edema and hemorrhage due to direct AVM, i.e., no capillary network between them). Group 3 (Clinically, it is impossible to distinguish arteries from veins due to severely dilated blood vessels all over retina). We present a 41-year-old male presented with a gradual decrease in his visual acuity in both eyes.

Keywords: Wyburn-Mason syndrome, arteriovenous malformation, macular edema.

Copyright @ 2020: This is an open-access article distributed under the terms of the Creative Commons Attribution license which permits unrestricted use, distribution, and reproduction in any medium for non-commercial use (NonCommercial, or CC-BY-NC) provided the original author and source are credited.

\section{Clinical PResentation}

A 41-year-old male patient complained of a gradual visual impairment in both eyes over the past six months. A review of systems was normal. No family records of any disease. Non-smoker and non-alcoholic. His visual acuity was 6/12 for the right (OD) and 6/18 for the left eye (OS), not corrected with glasses. Pupils were round, regular, reaction, and central with normal intraocular pressure in both eyes. No exophthalmos and no bruit were present. Dilated fundus examination of both eyes revealed bilateral dilated and tortuous vessels with AVM arising from the optic nerve (O.N.), the tortuosity fading gradually as going to the temporal regions with the presence of macular edema, fine multiple hard exudates, Figure 1a, and 1b. Optical coherence tomography (OCT) of the retina showed an AVM on the disc with intraretinal cysts and hyperreflective lesions in the inner retinal layers of the perifoveal and peripapillary regions suggestive hard exudates of dilated vessels in both the eyes, Fig $2 \mathrm{a}$ and 2b. The optical coherence tomography (OCTA) of the optic nerve showed AVM, Fig 3a and 3b. We diagnosed the case as incomplete Wyburn mason syndrome.

Due to allergy to fluorescein dye, we were unable to do Fluorescein fundus angiography and CTangiography scan of the brain, but we send him for medical consultation, they excluded the presence of hypertension, diabetes mellitus, and hypercoagulability status. 


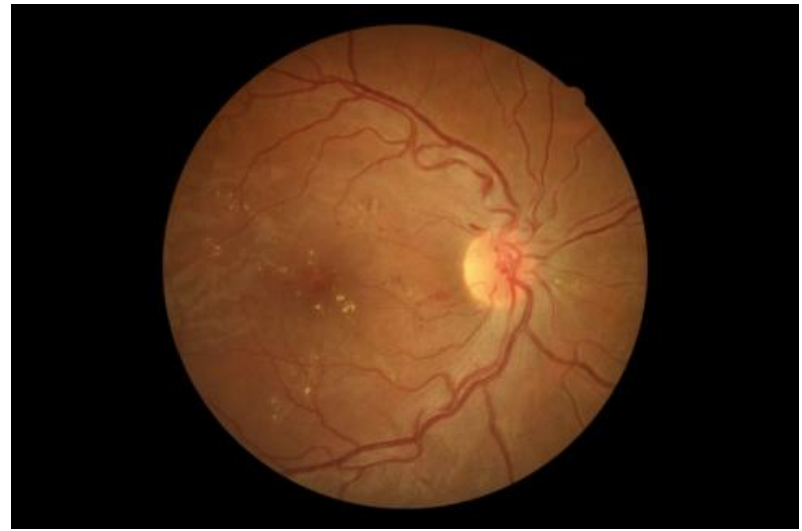

Fig-1a: Colored fundus image of the OD

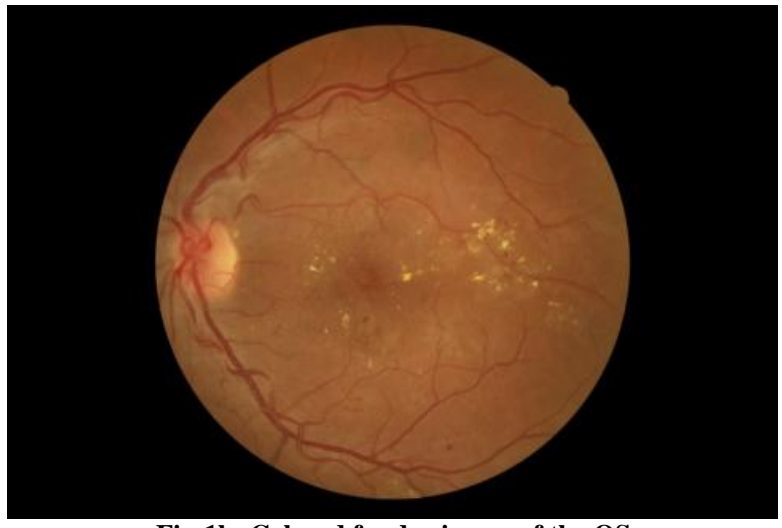

Fig-1b: Colored fundus image of the OS

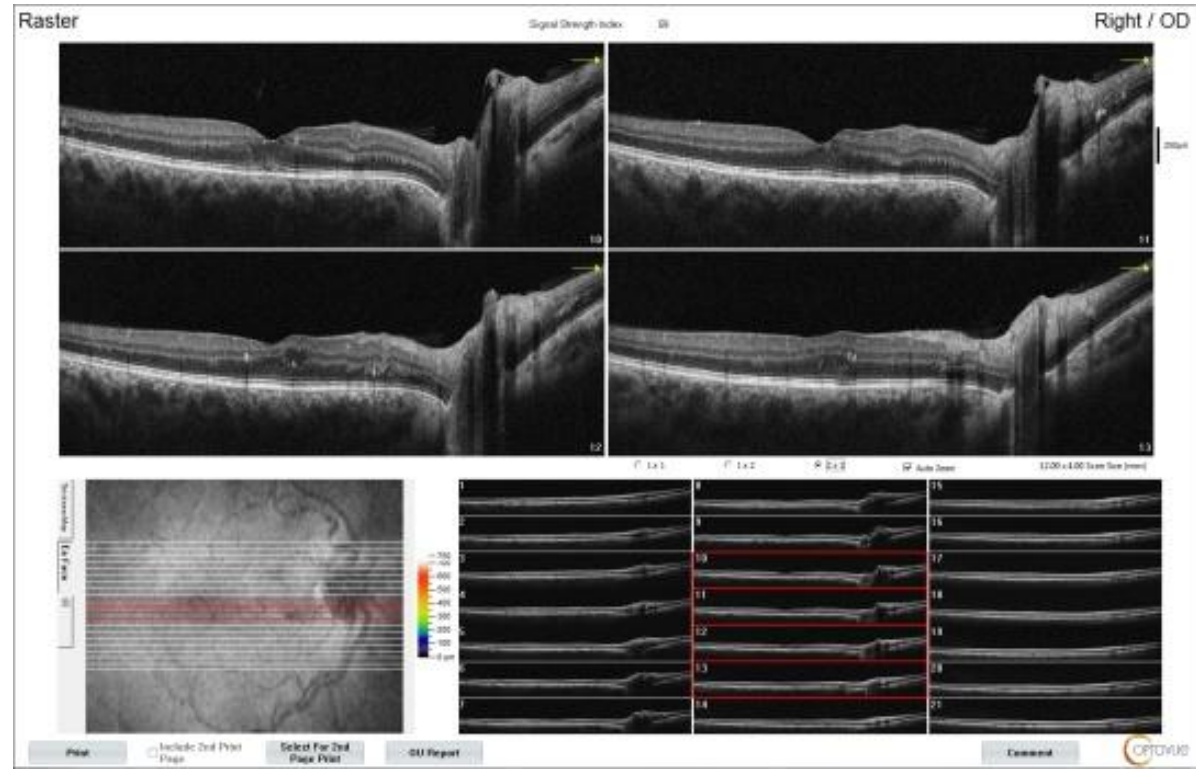

Fig-2a: OCT of the OD

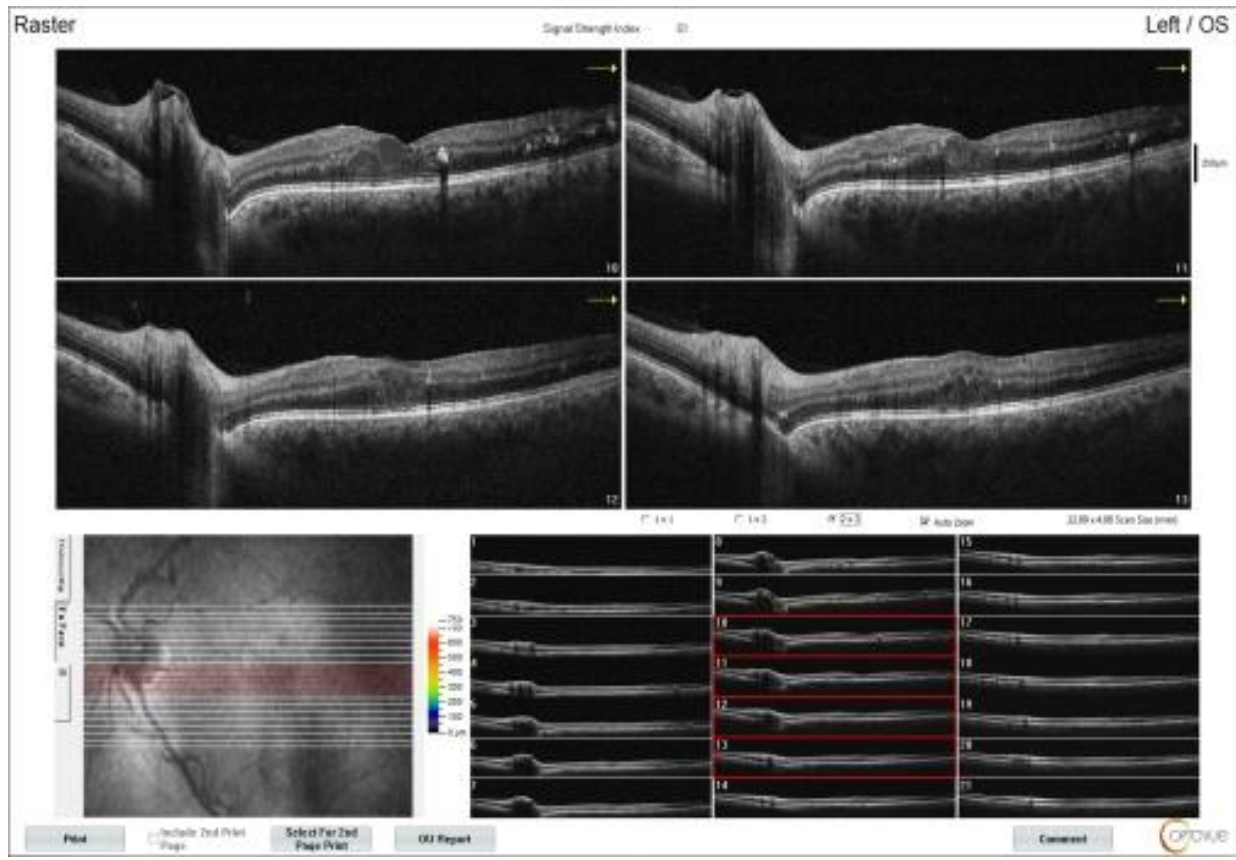

Fig-2b: OCT of the OS 


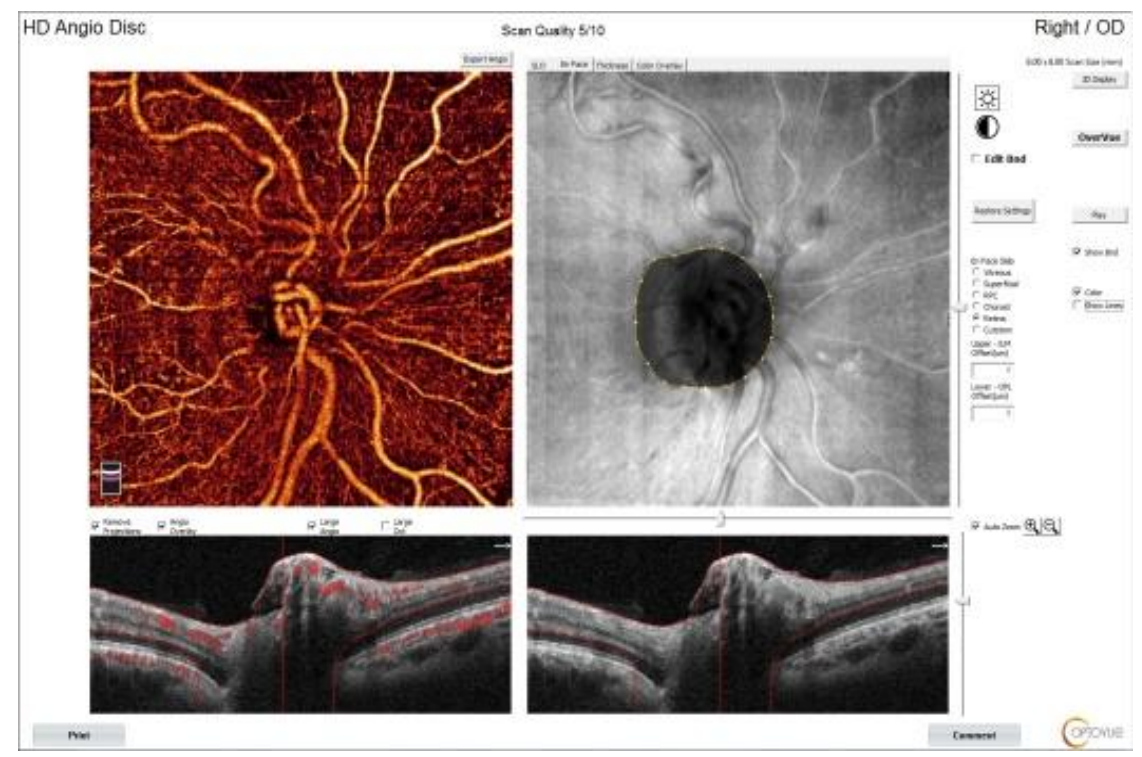

Fig-3a: OCTA of the right O.N.

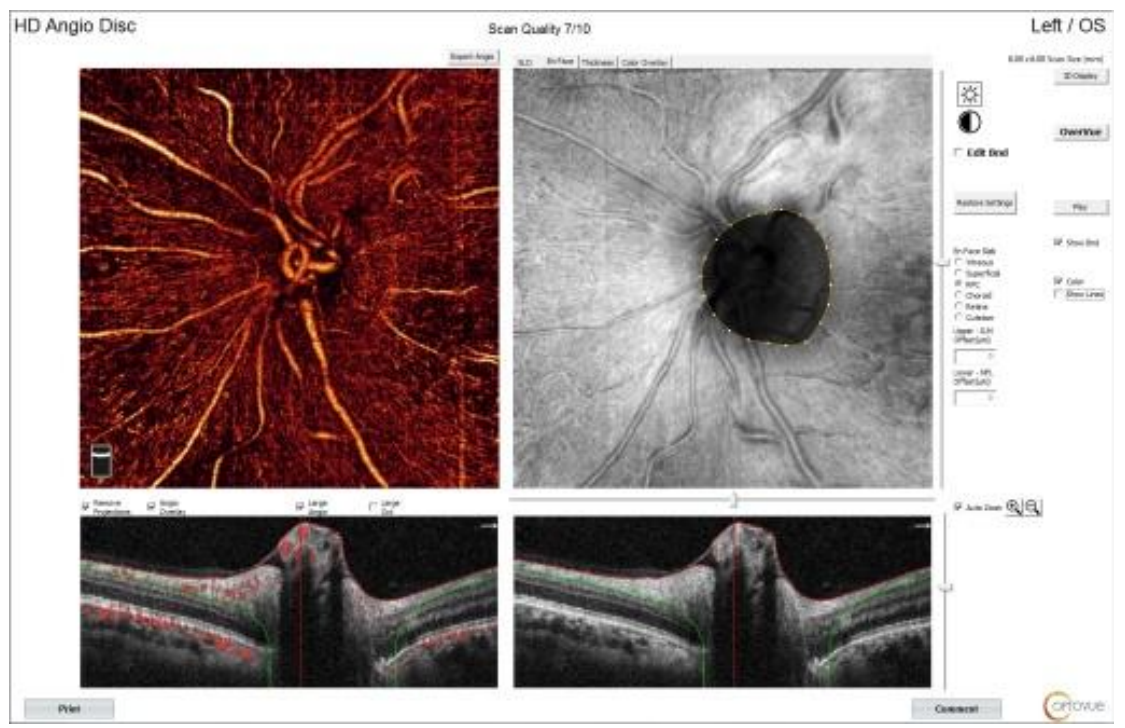

Fig-3b: OCTA of the left O.N.

\section{DISCUSSION}

The Wyburn-Mason syndrome is due to a fault in the primitive embryological structure known as mesoderm; this derivative forms the vascular structures, therefore, a defect can give rise to vascular malformations, it is usually unilateral, bilateral involvement is very rare [3]. In this report, our patient has a bilateral AV malformation, which involved both eyes equally [9]. Up to our knowledge, only nine cases of bilateral retinal hemangioma have been reported [3, $4,7]$. Usually, the mean age at presentation for females is 16 years and for males is 23 years. The symptoms among many of them start before this age, but our case presented at 41 years. All of the reported cases have symmetrical stages of involvement in both eyes like our case, but there is reported case with asymmetrical involvement of both eyes [10].

Soliman et al., explained the mechanism of macular edema in their study; they proposed that capillaries nearby the AVM might leak. The high arterial pressure transmits directly through the AV shunt to the connecting vein leading to an abnormal elevated venous pressure, which directly transfers to the healthy venous capillaries adjacent to the anastomosis ends with damaging and leakage [5, 7]. We carried out systemic work up to exclude other causes of macular edema.

Therefore, a decrease in vision can happen through many mechanisms, including macular edema and vitreous hemorrhage. Typically bleeding in retinal AVM does not occur (5). The bleeding can be secondary to complications: as the tortuosity can cause vascular occlusions, ischemia, ending with neovascularization, vitreous hemorrhage, and finally, neovascular glaucoma can happen [5, 11]. Our patient did not have any CNS symptoms; systemic involvement usually starts in early life [6]. 


\section{CONCLUSION}

Bilateral Wyburn-Mason syndrome can present outside the range of average presenting age. The presence of macular edema needs meticulous workup to exclude any concomitant illnesses.

\section{DECLARATIONS}

Funding: None

Conflict of interest: None declared

\section{REFERENCE}

1. Bhattacharya, J. J., Luo, C. B., Suh, D. C., Alvarez, H., Rodesch, G., \& Lasjaunias, P. (2001). Wyburn-Mason or Bonnet-Dechaume-Blanc as cerebrofacial arteriovenous metameric syndromes (CAMS) a new concept and a new classification. Interventional

Neuroradiology, 7(1), 5-17.

2. Patel, U., \& Gupta, S. C. (1990). Wyburn-Mason syndrome. Neuroradiology, 31(6), 544-546.

3. Schmidt, D., Pache, M., \& Schumacher, M. (2008). The congenital unilateral retinocephalic vascular malformation syndrome (BonnetDechaume-Blanc syndrome or Wyburn-Mason syndrome): review of the literature. Survey of ophthalmology, 53(3), 227-249.

4. Kaliki, S., Tyagi, M., \& Kumar, H. P. (2016). Bilateral peripapillary racemose hemangioma: An unusual presentation. Ophthalmology, 123(2), 323.

5. Onder, H. I., Alisan, S., \& Tunc, M. (2015, March). Serous retinal detachment and cystoid macular edema in a patient with Wyburn-Mason syndrome. In Seminars in ophthalmology, 30(2):154-156.

6. So, J. M., \& Holman, R. E. (2020). WyburnMason Syndrome. [Updated 2020 Feb 5]. In: StatPearls [Internet]. Treasure Island (FL): StatPearls Publishing; 2020 Jan-. Available from: https://www.ncbi.nlm.nih.gov/books/NBK493218/

7. Soliman, W., Haamann, P., \& Larsen, M. (2006). Exudation, response to photocoagulation and spontaneous remission in a case of bilateral racemose haemangioma. Acta Ophthalmologica Scandinavica, 84(3), 429-431.

8. Ruggieri, M. K. O., \& Rocco, C. (2008). WyburnMason Syndrome. In: Ruggieri, M., PascualCastroviejo, I., \& Di Rocco, C. (eds) Neurocutaneous Disorders Phakomatoses and Hamartoneoplastic Syndromes. Springer, Vienna.

9. Cortnum, S. O. S., Sørensen, P., \& Andresen, J. (2008). Bilateral Wyburn-Mason syndrome presenting as acute subarachnoid haemorrhage-a very rare congenital neurocutaneuos disorder. Acta neurochirurgica, 150(7), 725-727.

10. Pangtey, B. P., Kohli, P., \& Ramasamy, K. (2018). Wyburn-Mason syndrome presenting with bilateral retinal racemose hemangioma with unilateral serous retinal detachment. Indian journal of ophthalmology, 66(12), 1869-1871.

11. Mansour, A. M., Wells, C. G., Jampol, L. M., \& Kalina, R. E. (1989). Ocular complications of arteriovenous communications of the retina. Archives of Ophthalmology, 107(2), 232236. 